( 2018 , The Authors. Published by FASS Inc. and Elsevier Inc. on behalf of the American Dairy Science Association ${ }^{\circledR}$.

This is an open access article under the CC BY-NC-ND license (http://creativecommons.org/licenses/by-nc-nd/4.0/).

\title{
Influence of milk protein concentrates with modified calcium content on enteral dairy beverage formulations: Physicochemical properties
}

\author{
K. Pandalaneni, ${ }^{*}$ J. K. Amamcharla, ${ }^{* 1}$ C. Marella, $\dagger^{2}$ and L. E. Metzger† \\ *Department of Animal Sciences and Industry and Food Science Institute, Kansas State University, Manhattan 66506 \\ †Department of Dairy and Food Science, Midwest Dairy Foods Research Center, South Dakota State University, Brookings 57007
}

\begin{abstract}
Because of their high protein and low lactose content, milk protein concentrates (MPC) are typically used in the formulation of ready-to-drink beverages. Calciummediated aggregation of proteins during storage is one of the main reasons for loss of storage stability of these beverages. Control and calcium-reduced MPC [20\% calcium-reduced (MPC-20) and 30\% calcium-reduced (MPC-30)] were used to evaluate the physicochemical properties in this study. This study was conducted in 2 phases. In phase I, $8 \%$ protein solutions were prepared by reconstituting the $3 \mathrm{MPC}$ and adjusting the $\mathrm{pH}$ to 7. These solutions were divided into 3 equal parts, 0 , 0.15 , or $0.25 \%$ sodium hexametaphosphate (SHMP) was added, and the solutions were homogenized. In phase II, enteral dairy beverage formulations containing MPC and a mixture of gums, maltodextrin, and sugar were evaluated following the same procedure used in phase I. In both phases, heat stability, apparent viscosity, and particle size were compared before and after heat treatment at $140^{\circ} \mathrm{C}$ for $15 \mathrm{~s}$. In the absence of SHMP, MPC-20 and MPC-30 exhibited the highest heat coagulation time at 30.9 and $32.8 \mathrm{~min}$, respectively, compared with the control (20.9 min). In phase II, without any addition of SHMP, MPC-20 exhibited the highest heat coagulation time of 9.3 min compared with $7.1 \mathrm{~min}$ for control and $6.2 \mathrm{~min}$ for MPC-30. An increase in apparent viscosity and a decrease in particle size of reconstituted MPC solutions in phases I and II with an increase in SHMP concentration was attributed to casein micelle dissociation caused by calcium chelation. This study highlights the potential for application of calcium-reduced MPC in dairy-based ready-to-drink and enteral nutrition beverage formulations to improve their heat stability.
\end{abstract}

Key words: milk protein concentrate, dairy beverage, sodium hexametaphosphate, storage stability

Received March 20, 2018.

Accepted July 10, 2018.

${ }^{1}$ Corresponding author: jayendra@ksu.edu

${ }^{2}$ Current address: Idaho Milk Products, Jerome, ID 83338.

\section{INTRODUCTION}

Milk protein concentrate (MPC) is a preferred dairy ingredient in the food industry because of its protein content (50-85\%) and the presence of casein and whey proteins in the same ratio as milk. They are used as a major ingredient in protein beverages such as sports nutrition and shake-type products (Lagrange et al., 2015). Milk protein concentrates are the preferred source of protein in high-protein ready-to-drink and enteral nutrition formulas because they score high on protein quality. Their storage stability and shelf life depends on the composition and quality of ingredients used. It has been theorized that MPC solubility, protein-protein interactions during processing, and solubility changes during storage are influenced by the calcium content of the MPC (Marella et al., 2015). Additionally, issues during processing and subsequent storage of dairy beverages have been attributed to protein-protein and protein-mineral interactions (Augustin, 2000; Anema et al., 2006), leading to age gelation and phase separation in dairy beverages.

Several experiments have been carried out that reduced the calcium ion activity in MPC, either by addition of calcium chelators or by partial demineralization during ultrafiltration. Crowley et al. (2014) investigated the influence of $\mathrm{pH}$ and the addition of lactose and urea in the serum phase of reconstituted MPC solutions on heat stability. Those researchers observed that adding urea increased heat stability, whereas adding lactose and maltodextrin reduced heat stability at pH >6.9. Also, Fang et al. (2012) observed that the solubility of MPC powders was improved by reducing the inlet temperature during spray drying. Marella et al. (2015) also worked on improving the functionality of MPC by injecting carbon dioxide $\left(\mathrm{CO}_{2}\right)$ in skim milk before and during ultrafiltration. By injecting $\mathrm{CO}_{2}$, milk $\mathrm{pH}$ was reduced and solubilization of micellar calcium and phosphate was increased, resulting in reduced mineral content in the retentate fraction and, in turn, a calcium-reduced MPC that was reported to have better cold-water solubility. In another study to improve the functionality of MPC, Xu et al. (2016) 
Table 1. Composition (mean $\pm \mathrm{SD}$ ) of MPC powders used to formulate a high-protein enteral dairy beverage

\begin{tabular}{lcccc}
\hline MPC powder $^{1}$ & TS (\%) & Protein (\%) & Calcium (\%) & $\begin{array}{c}\text { Calcium } \\
\text { reduction (\%) }\end{array}$ \\
\hline Control & $94.73 \pm 0.18$ & $80.77 \pm 0.02$ & $2.21 \pm 0.04$ & - \\
MPC-20 & $95.13 \pm 0.89$ & $80.77 \pm 0.55$ & $1.73 \pm 0.02$ & 21.7 \\
MPC-30 & $94.70 \pm 0.17$ & $80.02 \pm 0.14$ & $1.47 \pm 0.02$ & 33.5 \\
\hline
\end{tabular}

${ }^{1}$ Control $=$ milk protein concentrate with $85 \%$ protein $(\mathrm{MPC}) ; \mathrm{MPC}-20=\mathrm{MPC}$ with $20 \%$ calcium reduction; MPC-30 $=$ MPC with $30 \%$ calcium reduction $(\mathrm{n}=2)$.

partially removed calcium in skim milk by ion-exchange treatment; at $83.6 \%$ decalcification, colloidal calcium phosphate (CCP) nanoclusters were completely dissociated. Ramchandran et al. (2017) improved the heat stability and emulsion capacity of MPC powders by pretreating skim milk with calcium chelating agents during ultrafiltration. This reduced the retentate calcium content and casein micelle size, thereby improving the functional properties of the MPC.

Because of improved heat stability and functional properties of MPC with reduced calcium content, this study was designed to evaluate their application in enteral dairy beverage formulations. Thus, MPC with different levels of calcium reduction along with varying levels of calcium chelating salts were used to study changes in the physiochemical properties of protein solutions.

\section{MATERIALS AND METHODS}

\section{Experimental Design}

Two batches of $0 \%$ (control), 20\% (MPC-20), and $30 \%$ (MPC-30) calcium-reduced milk protein concentrate with 85\% protein (MPC85) were obtained from Idaho Milk Products (Jerome, ID) with composition as shown in Table 1 . The MPC-20 is a commercially available calcium-reduced MPC known as IdaPlus 1085. Calcium-reduced MPC were manufactured by injecting $\mathrm{CO}_{2}$ into pasteurized skim milk before ultrafiltration according to the method of Marella et al. (2015). This study was a split-plot design with 3 types of MPC (control, MPC-20, and MPC-30) with $85 \%$ protein content on a dry basis (MPC85) and 2 replicates considered as a whole plot. Three levels ( $0,0.15$, and $0.25 \% \mathrm{wt} / \mathrm{wt})$ of sodium hexametaphosphate (SHMP) were considered as the sub-plot. The effects of SHMP and calciumreduced MPC on heat stability, apparent viscosity, and particle size were studied in 2 phases and in duplicate. In phase I, reconstituted solutions were prepared using only MPC with 3 levels of calcium. In phase II, an enteral nutrition dairy formulation containing MPC was evaluated (Table 2).

\section{Phase I}

Control and calcium-reduced MPC were reconstituted in distilled water to make $8 \%$ (wt/wt) protein in the final solution. The reconstitution was carried out at approximately $45^{\circ} \mathrm{C}$ and the solution was maintained at $45^{\circ} \mathrm{C}$ under constant stirring for 30 min using a magnetic stirrer. The $\mathrm{pH}$ of the reconstituted MPC was adjusted to 7.0 using $0.5 \mathrm{~N} \mathrm{NaOH}$ when $\mathrm{pH}$ was $<7.0$, and no $\mathrm{pH}$ adjustments were made for solutions when $\mathrm{pH}$ was $>7.0$. The average $\mathrm{pH}$ recorded was 7.19 for the solutions with $\mathrm{pH}>7.0$. The $\mathrm{pH}$-adjusted solutions were divided into 3 equal parts and mixed with 0, 0.15 , or $0.25 \%$ SHMP under constant stirring for an additional $10 \mathrm{~min}$. Subsequently, the samples were homogenized using a handheld homogenizer (Polytron

Table 2. Enteral dairy beverage formulation used in preparation of phase II formulations

\begin{tabular}{|c|c|c|}
\hline Ingredient & $\%$ & Source \\
\hline $\mathrm{MPC} 85^{1}$ & 9.76 & Idaho Milk Products (Jerome, ID) \\
\hline Corn maltodextrin & 2.90 & Maltrin M100, GPC (Muscatine, IA) \\
\hline Sugar (sucrose) & 1.21 & C\&H Sugar (Crockett, CA) \\
\hline Canola oil & 0.68 & Crisco, The J. M. Smucker Co. (Orrville, OH) \\
\hline Potassium citrate & 0.12 & Sigma Aldrich (St. Louis, MO) \\
\hline Cellulose gum & 0.12 & Ticacel-700 MCC, TIC Gums Inc. (White Marsh, MD) \\
\hline Carrageenan & 0.02 & Ticaloid 100, TIC Gums Inc. \\
\hline Cellulose gel & 0.02 & Ticacel-700 MCC, TIC Gums Inc. \\
\hline Gellan gum & 0.12 & Ticagel Gellan DPB, TIC Gums Inc. \\
\hline Water & 85.05 & \\
\hline Total & 100.00 & \\
\hline
\end{tabular}


PT 2500 E, Luzern, Switzerland) at 5,000 rpm for $30 \mathrm{~s}$ to achieve a stable emulsion. Homogenized MPC solutions were further divided into 2 equal parts (unheated and heat-treated). One part was poured into $6-\mathrm{mL}$ glass vials and brought to $140^{\circ} \mathrm{C}$ in an oil bath for 15 $\mathrm{s}$ and immediately transferred to an ice bath to cool. The time required to bring the solution in $6-\mathrm{mL}$ vials to $140^{\circ} \mathrm{C}$ was determined during preliminary experiments. The heated glass vials were then used to measure apparent viscosity, particle size, and color to determine the effect of heat treatment. The unheated portion was used to measure heat coagulation time (HCT), apparent viscosity, particle size, and color.

\section{Phase II}

An enteral dairy-based beverage was formulated using control and calcium-reduced MPC to prepare $8 \%$ (wt/wt) protein in the final formulation. The other ingredients in the formulation included corn maltodextrin, sugar (sucrose), canola oil, potassium citrate, and gums. The composition of the enteral formulation used in phase II is shown in Table 2. The $\mathrm{pH}$ of the formulations was adjusted to 7.0 when the $\mathrm{pH}$ was $<7.0$, following the same procedure as in phase I. Further division into 3 equal parts and subsequent addition of SHMP, homogenization, and analysis of physical properties of heated and unheated samples was followed as described for phase I.

\section{Apparent Viscosity}

The apparent viscosity of the heated and unheated solutions from phases I and II was measured using a controlled stress rheometer (ATS RheoSystems, NJ) with bob-and-cup configuration with $13 \mathrm{~mL}$ of sample. Apparent viscosity was measured at $20^{\circ} \mathrm{C}$ at a shear rate of $100 \mathrm{~s}^{-1}$ and compared statistically.

\section{Particle Size}

The particle size of the heated and unheated solutions from phase I and II solutions was measured using the dynamic light scattering (DLS) technique with a Zetasizer Nano ZSP (Malvern Instruments Ltd., Malvern, UK) using a method adapted from Silva et al. (2001). Samples were diluted 50 times in calcium imidazole buffer to avoid rapid dissolution of samples and transferred into a disposable cuvette for analysis. This system was equipped with a helium/neon laser at a wavelength of $633 \mathrm{~nm}$ and a backscattering angle of $173^{\circ}$ at $10 \mathrm{~mW}$. Particle size was measured at $25^{\circ} \mathrm{C}$ at 20 -s intervals for 2 repeated measurements. The autocorrelation function of the intensity scattering from the particles calculated the mean hydrodynamic diameter (Z-average mean). In the bimodal distribution obtained, a second peak in the range of 3,000 to $6,000 \mathrm{~nm}$ that was contributed by fat was ignored when calculating the Z-average mean.

\section{Color}

Lightness (whiteness, $\mathbf{L}^{*}$ ), green to red color (negative-to-positive scale, $\mathbf{a}^{*}$ ), and blue to yellow color (negative-to-positive scale, $\mathbf{b}^{*}$ ) values of heated and unheated MPC solutions in phase I and II were measured using a colorimeter (HunterLab, Miniscan XE, Reston, VA). The colorimeter was calibrated against white and green standards (Nasirpour et al., 2006).

\section{Heat Stability}

A sample volume of $3 \mathrm{~mL}$ was transferred into a glass tube and capped securely before immersion in an oil bath (Narang Scientific Works Pvt. Ltd., New Delhi, India). Tubes were placed on the rocking frame and placed in the oil bath at $140^{\circ} \mathrm{C}$ to determine HCT. Heat coagulation time (minutes) was defined as the time required for visual coagulation of the sample after it was placed in an oil bath at the given temperature (Singh, 2004).

\section{Statistical Analysis}

Statistical analysis of replicates was performed using SAS software (version 9.1, SAS Institute Inc., Cary, NC). PROC GLIMMIX was used for the analysis and Tukey's test was used to determine differences between treatments, which were declared significant when $P \leq$ 0.05 .

\section{RESULTS AND DISCUSSION}

Casein micelles are composed of submicelles consisting of casein proteins bound together by hydrophobic interactions and CCP (Chandrapala, 2009). In a stable milk system, a mineral equilibrium exists between colloidal and serum phases, which determines casein micelle integrity. However, when a chelating agent is added to the milk system, the chelating agent binds to ionic calcium and disturbs the mineral equilibrium between the colloidal and serum phases and additional calcium migrates into the serum phase. At this stage, the casein micelle is still intact due to hydrophobic interactions. On chelation of calcium above a critical level, casein micelles destabilize and dissociate as submicelles (Panouillé et al., 2004) as shown in mechanism 


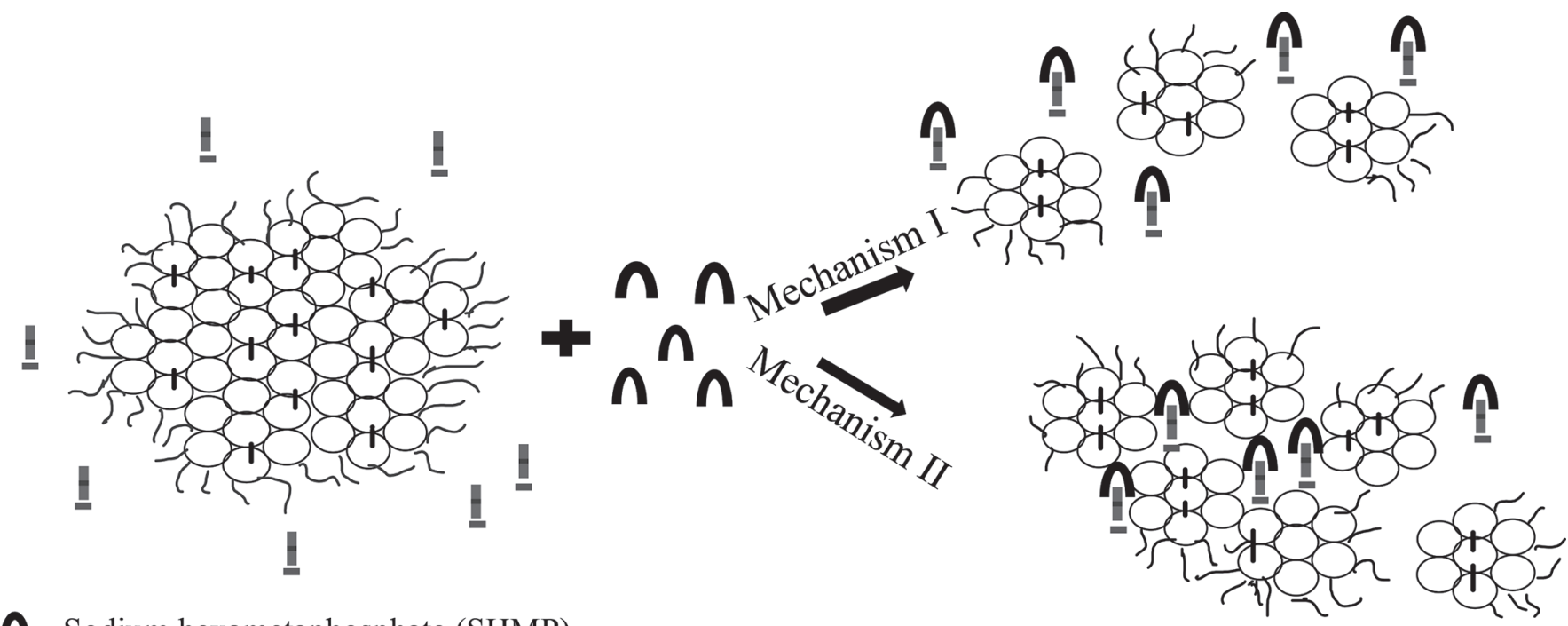

ก Sodium hexametaphosphate (SHMP)

- Colloidal calcium phosphate (CCP)

א-casein, outer hairy layer of casein micelle

88 Casein sub-micelle

Ionic calcium

A Ionic calcium-SHMP complex

Figure 1. Illustration of the interaction between casein micelle and sodium hexametaphosphate (SHMP). Mechanism I: at low concentrations of SHMP, casein micelles are dissociated; Mechanism II: at high concentrations of SHMP, calcium-casein phosphate complexes form.

I of Figure 1. According to Pitkowski et al. (2008), the extent of dissociation depends on the concentration of casein and the concentration and type of chelating salt. They also suggested that dissociation of casein micelles was a cooperative process; that is, casein micelles were either fully dissociated or remained intact until a critical level of calcium was chelated. Pitkowski et al. (2008) and Griffin et al. (1988) suggested that calcium can be chelated from the casein micelle in lower amounts without disturbing the integrity of casein micelles; however, casein micelles can completely dissociate at higher concentrations of chelating agents such as SHMP.

In addition to chelating calcium, SHMP can crosslink with casein proteins because of its 6 negative charges and homogeneous charge distribution. When SHMP is present in higher concentrations, it also forms calciumcasein phosphate complexes in the presence of calcium (McCarthy et al., 2017) as shown in Figure 1 (mechanism II). Understanding the role of calcium, caseins, and SHMP as a chelator improves our understanding of the changes in the physical and functional properties of high-protein dairy beverages.

\section{Phase I: Apparent Viscosity}

Unheated MPC Solutions. The apparent viscosity results are shown in Table 3. Apparent viscosity of control MPC solution showed no significant difference between 0\% SHMP $(6.62 \mathrm{cP})$ and $0.15 \%$ SHMP $(15.85$ cP) but apparent viscosity increased significantly $(P<$ $0.05)$ as SHMP concentration increased to 0.25\% (56.54 cP). Similarly, in MPC-20, apparent viscosity did not change as SHMP concentration increased from 0 to $0.15 \%$ but increased from 5.04 to $29.70 \mathrm{cP}$ when SHMP concentration increased from 0 to $0.25 \%$. Increase in apparent viscosity of control and MPC-20 solutions occurred because of the diffusion of caseins into the serum phase due to dissociation of casein micelles after addition of SHMP. McCarthy et al. (2017) observed that, after the addition of SHMP to $5 \%$ MPC solutions, apparent viscosity increased because of calcium chelation and casein cross-links formed via calcium-casein phosphate complexes in the serum phase. CalciumSHMP complex formation prevents the interaction of calcium with caseins and inhibits aggregation. On the 
Table 3. Apparent viscosity (cP; mean $\pm \mathrm{SD}$ ) of unheated and heated solutions at $100 \mathrm{~s}^{-1}$ shear rate in phase I and II

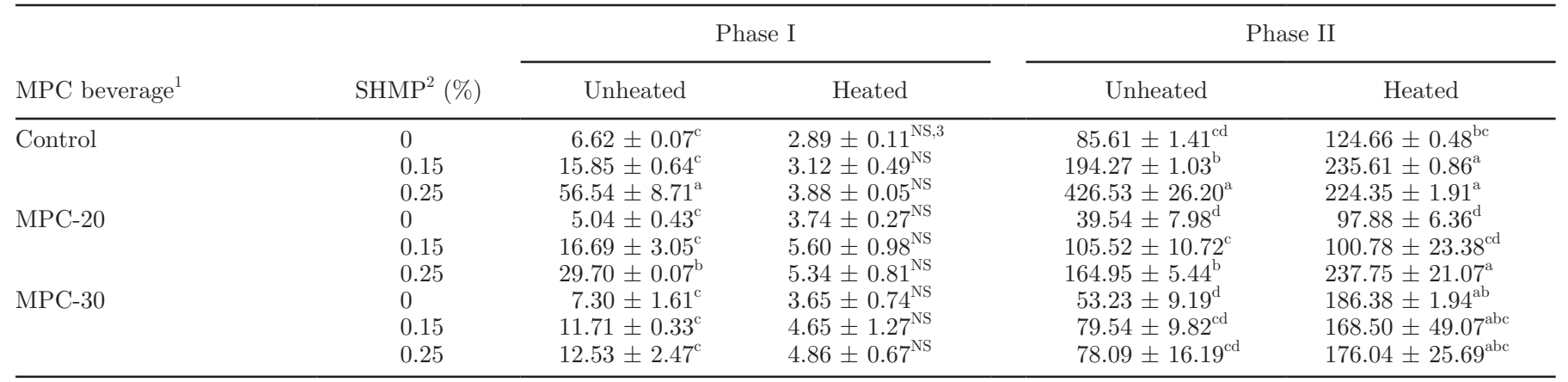

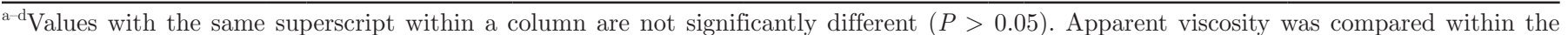
column.

${ }^{1}$ Control $=$ milk protein concentrate with $85 \%$ protein $(\mathrm{MPC}) ; \mathrm{MPC}-20=\mathrm{MPC}$ with $20 \%$ calcium reduction; MPC- $30=\mathrm{MPC}$ with $30 \%$ calcium reduction.

${ }^{2}$ Sodium hexametaphosphate.

${ }^{3}$ No significant interaction effect between main effects.
}

other hand, MPC-30 had viscosities in the range of 7.30 to $12.53 \mathrm{cP}$, with no significant difference at any level of SHMP because of the lower calcium levels, leading to easy dissociation of casein micelles. Similarly, in the absence in SHMP, the viscosities of control, MPC-20, and MPC-30 did not differ.

Apparent viscosity of solutions did not increase significantly as SHMP concentration increased from 0 to $0.15 \%$ in control, MPC-20, or MPC-30. This implies that the extent of casein micelle dissociation was the same in all 3 beverages at $0.15 \%$ SHMP. However, when $0.25 \%$ SHMP was added, apparent viscosity of control increased by 9 -fold, whereas MPC-20 had an increase of only 6 -fold. On the other hand, apparent viscosity did not increase in MPC-30 at any level of SHMP studied. The greater increase in the control was assumed to be due to the presence of more calcium than in MPC-20 and MPC-30. We theorize that the presence of higher calcium in the control resulted in calcium-casein phosphate complexes as the SHMP concentration increased to $0.25 \%$, resulting in an increase in apparent viscosity, as described by mechanism II of Figure 1. de Kort et al. (2011) and McCarthy et al. (2017) also observed a strong affinity of SHMP not just toward calcium but also toward caseins. As calcium decreased in MPC-20 and MPC-30, dissociation of casein micelles occurred easily along with minimum formation of calcium-casein phosphate complexes, as shown in mechanism I from Figure 1. Due to the minimum formation of calciumcasein phosphate complexes, apparent viscosity of solutions with MPC-30 and MPC-20 containing 0.25\% SHMP did not increase as much as in control.

Heated MPC Solutions. Heated MPC solutions showed no significant interaction effect between main effects; that is, the calcium concentration and SHMP concentration. We observed no difference in viscosities of the MPC solutions, which ranged from 2.89 to 3.88 $\mathrm{cP}$ in control, 3.74 to $5.34 \mathrm{cP}$ in MPC-20, and 3.65 to $4.86 \mathrm{cP}$ in MPC-30. Hence, these results will not be further discussed. We assumed that the reduced calcium in MPC and addition of a strong chelating agent such as SHMP dissociated the casein micelles to a greater extent and that interaction among denatured whey proteins and reaggregation of casein micelles did not influence the beverages' viscosity.

\section{Phase I: Particle Size}

Unheated MPC Solutions. Particle size of heated and unheated MPC solutions is given in Table 4. A significant $(P<0.05)$ decrease in particle size was observed in the control as the concentration of SHMP increased. Particle size decreased from 192 to $90 \mathrm{~nm}$ when $0.15 \%$ SHMP was added, but only decreased to $82 \mathrm{~nm}$ with $0.25 \%$ SHMP. This observed decrease in particle size occurred because of the dissociation of casein micelles into submicelles and nonmicellar casein proteins as calcium was chelated by SHMP (Panouillé et al., 2004; Mizuno and Lucey, 2005; de Kort et al., 2011; Kaliappan and Lucey, 2011). Similarly, in MPC-20, particle size decreased from 186 to $87 \mathrm{~nm}$ with $0.15 \%$ SHMP and to $76 \mathrm{~nm}$ with $0.25 \%$ SHMP. For MPC-30, there was a significant $(P<0.05)$ decrease in particle size with $0.15 \%$ SHMP (from 108 to $83 \mathrm{~nm}$ ) with no further significant decrease as SHMP increased to $0.25 \%$. Particle size decreases in control, MPC-20, and MPC-30 with increasing SHMP concentration support the apparent viscosity results. It is evident from the apparent viscosity and particle size data that calcium percentage in MPC influences the extent of casein micelle dissocia- 
Table 4. Particle size (nm; mean $\pm \mathrm{SD}$ ) of unheated and heated solutions in phase I and II

\begin{tabular}{|c|c|c|c|c|c|}
\hline $\mathrm{MPC}^{1}$ & $\mathrm{SHMP}^{2}(\%)$ & \multicolumn{2}{|c|}{ Phase I } & \multicolumn{2}{|c|}{ Phase II } \\
\hline Control & $\begin{array}{l}0 \\
0.15 \\
0.25\end{array}$ & $\begin{array}{r}192.14 \pm 0.59^{\mathrm{a}} \\
90.71 \pm 0.77^{\mathrm{d}} \\
82.13 \pm 1.05^{\mathrm{f}}\end{array}$ & $\begin{array}{l}229.04 \pm 8.25^{\mathrm{e}} \\
380.24 \pm 2.64^{\mathrm{a}} \\
337.12 \pm 1.77^{\mathrm{b}}\end{array}$ & $\begin{array}{l}236.08 \pm 1.98^{\mathrm{a}} \\
176.35 \pm 4.84^{\mathrm{b}} \\
123.00 \pm 1.03^{\mathrm{f}}\end{array}$ & $\begin{array}{l}263.45 \pm 1.52^{\mathrm{c}} \\
259.28 \pm 5.80^{\mathrm{cd}} \\
246.44 \pm 4.61^{\mathrm{d}}\end{array}$ \\
\hline MPC-20 & $\begin{array}{l}0 \\
0.15 \\
0.25\end{array}$ & $\begin{aligned} 186.61 & \pm 1.07^{\mathrm{b}} \\
87.52 & \pm 0.49^{\mathrm{de}} \\
76.65 & \pm 2.66^{\mathrm{g}}\end{aligned}$ & $\begin{array}{l}235.47 \pm 4.24^{\mathrm{e}} \\
270.29 \pm 5.71^{\mathrm{c}} \\
223.45 \pm 5.27^{\mathrm{e}}\end{array}$ & $\begin{array}{l}163.09 \pm 1.01^{\mathrm{c}} \\
148.43 \pm 1.24^{\mathrm{d}} \\
126.18 \pm 3.91^{\mathrm{ef}}\end{array}$ & $\begin{array}{l}252.86 \pm 1.57^{\mathrm{cd}} \\
225.26 \pm 3.38^{\mathrm{e}} \\
214.69 \pm 1.71^{\mathrm{e}}\end{array}$ \\
\hline
\end{tabular}

${ }^{\mathrm{a}-\mathrm{h}}$ Values with the same superscript within a column are not significantly different $(P>0.05)$. Particle size was compared within the column. ${ }^{1}$ Control $=$ milk protein concentrate with $85 \%$ protein $(\mathrm{MPC}) ; \mathrm{MPC}-20=\mathrm{MPC}$ with $20 \%$ calcium reduction; $\mathrm{MPC}-30=\mathrm{MPC}$ with $30 \%$ calcium reduction.

${ }^{2}$ Sodium hexametaphosphate.

tion: the lower the calcium percentage, the higher the amount of dissociated casein micelles. These observations also support the apparent viscosity findings in that the presence of larger particles in the control can be attributed to $\mathrm{CCP}$ keeping micelles intact, whereas in MPC-20 and MPC-30, micelles dissociated faster due to reduced calcium, even in the absence of SHMP. Although significant dissociation of casein micelles was observed in the absence of SHMP, it did not influence the apparent viscosity of the MPC solutions.

Heated MPC Solutions. Particle size in MPC solutions increased after heat treatment due to heat-induced interactions between proteins. The increase in particle size is attributed to reaggregation of dissociated casein micelles among themselves and with denatured whey proteins (Singh and Fox, 1987). The increase in particle size was also the result of deposition of precipitated calcium phosphate on the casein micelles (Chen and O'Mahony, 2016). When reconstituted MPC solutions were heated in phase I, the particle size of the control increased significantly $(P<0.05)$ as SHMP concentration increased from 0 to $0.15 \%$ and then decreased as SHMP increased to $0.25 \%$. A similar trend was detected in MPC-20 and MPC-30 as well, where particle size increased with $0.15 \%$ SHMP due to reaggregation of proteins. Particle size decreased upon addition of $0.25 \%$ SHMP due to casein micelle dissociation. On the other hand, in the absence of SHMP, particle size in control $(229.04 \mathrm{~nm})$, MPC-20 (235.47 nm), and MPC$30(229.16 \mathrm{~nm})$ did not differ. This suggests that in the absence of SHMP, the reduced calcium in the MPC did not affect particle size.

\section{Phase l: Color}

Unheated MPC Solutions. To emphasize the change in lightness of MPC solutions, only $\mathrm{L}^{*}$ values are discussed (we found no significant interactions between main effects, MPC type and Ca concentration, in $a^{*}$ and $\left.b^{*}\right)$. Measured $L^{*}$ values of unheated and heated MPC solutions in phase I are shown in Table 5. Whiteness and turbidity of milk are attributed to the polydisperse casein micelles. Dissociation of casein micelles decreases both whiteness and turbidity and thus reduces L* values (Kaliappan and Lucey, 2011; McCarthy et al., 2017). We found no significant difference in $\mathrm{L}^{*}$ of control MPC at any level of SHMP studied, with values ranging from 73 to 75 . Similar observations were made in MPC-20, with no significant differences observed in $\mathrm{L}^{*}$ values. The MPC-30 solutions with 0 and $0.15 \%$ SHMP had no significant $(P<0.05)$ difference in $\mathrm{L}^{*}$ values but a significant difference was observed in MPC-20 with addition of $0.25 \%$ SHMP, with this sample having the lowest $\mathrm{L}^{*}$ value of 58 , which was caused by reduced opacity of the solution due to casein micelle dissociation caused by calcium chelation.

Heated MPC Solutions. Lightness values of control solutions did not differ when SHMP concentration increased from 0 to $0.15 \%$ but decreased significantly (from 76 to $64 ; P<0.05$ ) at $0.25 \%$ SHMP. In MPC-20, $\mathrm{L}^{*}$ decreased as SHMP concentration increased from 0 to $0.15 \%$ to $0.25 \%$, and a similar observation was made in MPC-30. This decrease in $\mathrm{L}^{*}$ was attributed to increasing translucency of the solutions due to casein micelle dispersion as SHMP concentration increased (Crudden et al., 2005). In the absence of SHMP, L* values did not differ between control, MPC-20, and MPC-30.

\section{Phase I: Heat Stability}

Heat stability is an important attribute to consider when evaluating processing parameters and stability of proteins in milk systems. When milk is heated to high 
Table 5. Whiteness ( $\mathrm{L}^{*}$; mean $\left.\pm \mathrm{SD}\right)$ of unheated and heated solutions in phases I and II

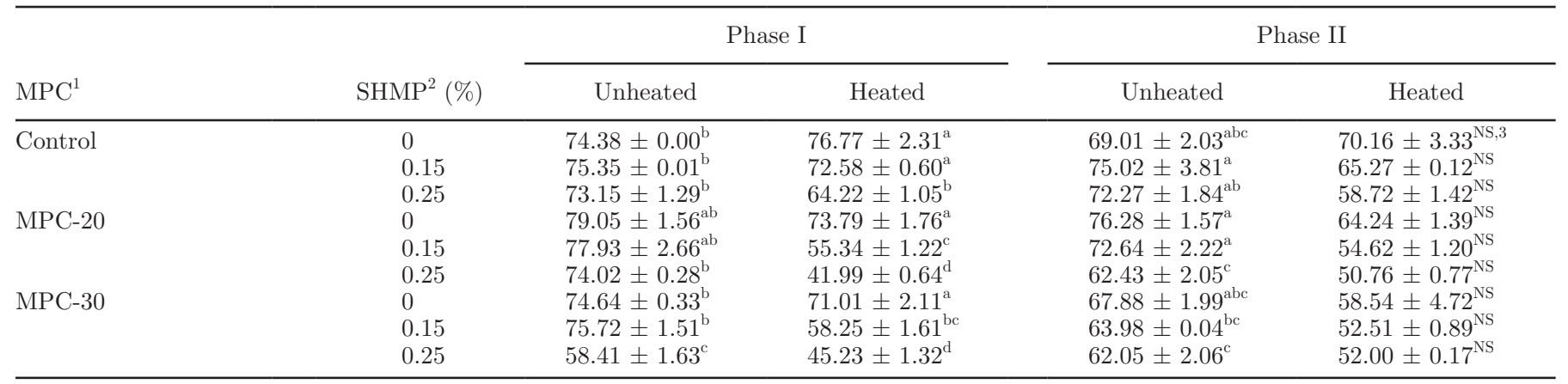

\footnotetext{
${ }^{a-d}$ Values with the same superscript within a column are not significantly different $(P>0.05)$. Whiteness $\left(L^{*}\right)$ was compared within the same phase for statistical purposes.

${ }^{1}$ Control $=$ milk protein concentrate with $85 \%$ protein $(\mathrm{MPC}) ; \mathrm{MPC}-20=\mathrm{MPC}$ with $20 \%$ calcium reduction; MPC-30 $=\mathrm{MPC}$ with $30 \%$ calcium reduction.

${ }^{2}$ Sodium hexametaphosphate.

${ }^{3}$ No significant interaction effect between main effects.
}

temperatures $\left(120\right.$ to $\left.140^{\circ} \mathrm{C}\right)$, changes in mineral equilibria between the serum and colloidal phases, along with dissociation of $\kappa$-casein from the casein micelle surface, can lead to steric destabilization of casein micelles. At $\mathrm{pH}>6.9$, heat-induced coagulation is sensitive to calcium ion concentration in $\kappa$-casein-depleted casein micelles (Singh, 2004). Calcium ion concentration, pH, and protein concentration are important factors that determine heat stability in milk systems. At $\mathrm{pH}>6.7$, Crowley et al. (2014) observed a significant $(P<0.05)$ decrease of approximately $20 \mathrm{~min}$ in $\mathrm{HCT}$ at $140^{\circ} \mathrm{C}$ in $3.5 \%$ reconstituted solutions prepared from MPC in the range of MPC35 to MPC90. This decreased HCT was due to an increase in calcium ion activity along with heat-induced dissociation of $\kappa$-casein. To improve the heat stability of milk systems, especially dairy beverages, calcium chelators are added to reduce the free calcium ion concentration and decrease susceptibility to ultra-high temperatures during processing (Kaliappan and Lucey, 2011).

In this study, dominating factors that could change mineral equilibria included the concentrations of calcium in MPC and SHMP. The HCT of the MPC solutions in phase I are shown in Figure 2. In the control samples, a significant $(P<0.05)$ increase in HCT was only observed when SHMP concentration increased from 0 (20.9 $\mathrm{min})$ to $0.25 \%$ (28 $\mathrm{min})$. Calcium chelating salts such as SHMP decrease the availability of free calcium ions in the serum phase, thereby reducing the calcium-mediated aggregation of caseins (Augustin and Clarke, 1990). We observed no difference in HCT of MPC-20 and MPC-30 at different levels of SHMP; measured HCT were in the range of 30 to 33 min. Absence of an increase in $\mathrm{HCT}$ upon increase in SHMP concentration in MPC-20 and MPC-30 was due to the disruption of casein micellar structural integrity as SHMP concentration increased, resulting in rapid coagulation. de Kort et al. (2012) observed that HCT of a $9 \%(\mathrm{wt} / \mathrm{vol})$ micellar casein isolate solution at $\mathrm{pH}$ 7.0 decreased as SHMP concentration increased. As a SHMP concentration $>7.5 \mathrm{mmol} / \mathrm{L}(0.45 \% \mathrm{wt} / \mathrm{vol})$ was used, calcium was completely chelated, resulting in complete dissociation of casein micelles and leading to a faster coagulation and lower HCT (de Kort et al., 2012).

In the absence of SHMP, HCT increased by 10 and $12 \mathrm{~min}$ in MPC-20 and MPC-30, respectively, compared with control. This significant increase in HCT can be attributed to the reduced calcium content of the MPC, which increased casein micelle stability at higher temperatures. These results support the fact that calcium concentration in MPC plays a key role in determining HCT of reconstituted MPC solutions. Faka et al. (2009) observed an increase in heat stability during in-can sterilization of $25 \%$ reconstituted lowheat skim milk when the calcium ion concentration was reduced. Those authors also concluded that calcium ion concentration played a more important role than $\mathrm{pH}$ in improving heat stability during in-can sterilization of reconstituted skim milk. These results suggest that heat stability of reconstituted MPC solutions can be significantly improved by using calcium-reduced MPC rather than adding chelating salts such as SHMP.

\section{Phase II: Apparent Viscosity}

Unheated Formulations. Apparent viscosity increased in phase II formulations of control and MPC-20 as SHMP concentration increased, following the same trend as observed for phase I (Table 3). Apparent vis- 


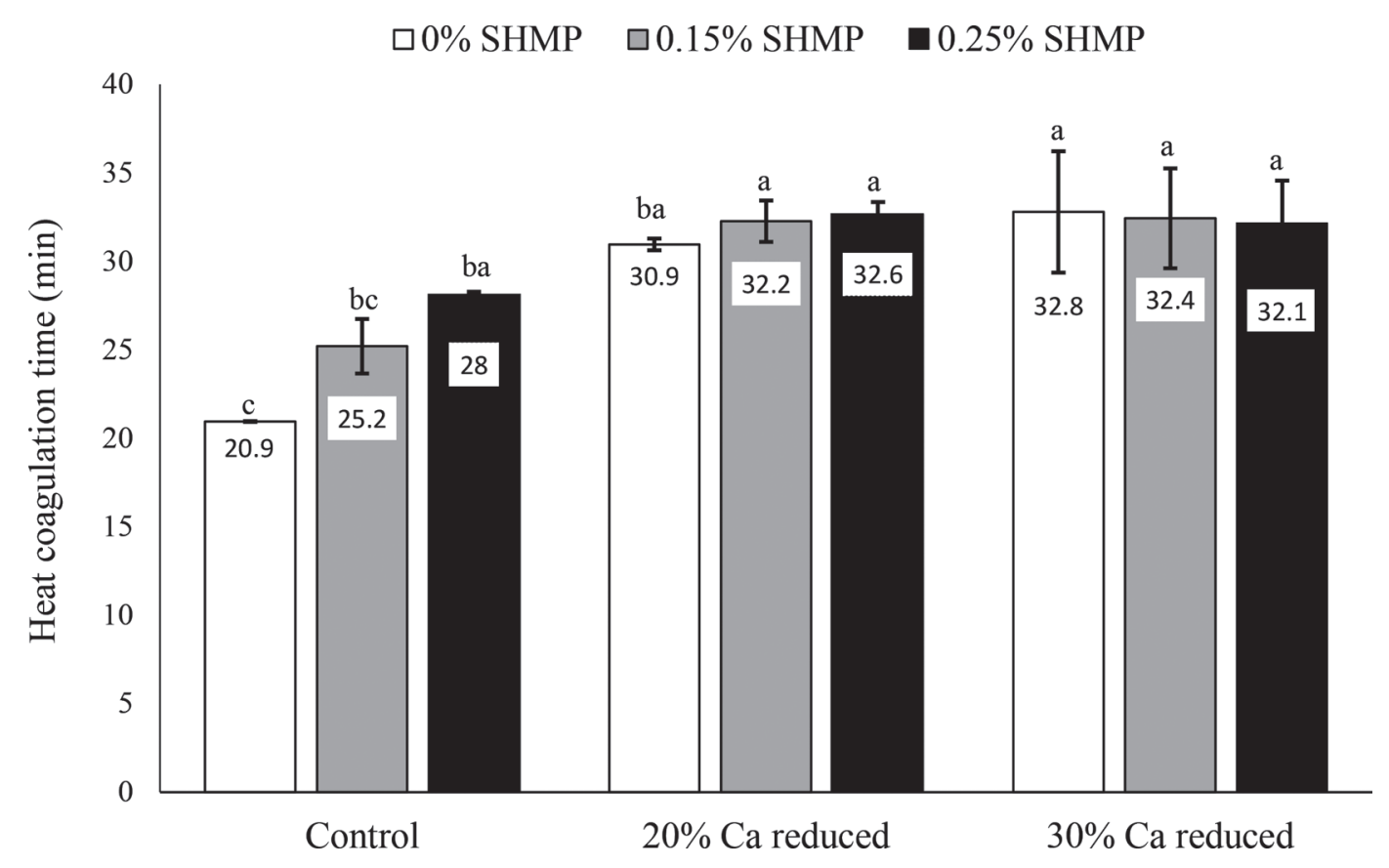

Figure 2. Heat coagulation time (HCT; min) of solutions prepared using control, 20\% calcium-reduced milk protein concentrate (MPC-20), and 30\% calcium-reduced MPC (MPC-30) in 8\% protein MPC solutions of phase I with sodium hexametaphosphate (SHMP) at different levels. Values with the same letters $(\mathrm{a}-\mathrm{c})$ are not significantly different across all treatments $(P>0.05)$. Error bars represent SD $(\mathrm{n}=2)$.

cosity in control MPC formulations showed a significant $(P<0.05)$ increase from 85.61 to $194.27 \mathrm{cP}$ as SHMP increased to $0.15 \%$, and the highest apparent viscosity $(426.53 \mathrm{cP})$ was observed in the formulation with $0.25 \%$ SHMP. As described in mechanism II of Figure 1 , the extremely high apparent viscosity in control with $0.25 \%$ SHMP was due to the calcium-binding and cross-linking ability of SHMP (McCarthy et al., 2017).

Apparent viscosity of the MPC-20 formulation increased significantly $(P<0.05)$ from 39.54 to 105.52 cP with $0.15 \%$ SHMP, and further increased to 164.95 cP with $0.25 \%$ SHMP. In MPC-30, we observed no significant difference in apparent viscosity at any SHMP concentration studied. However, for the phase II formulations compared with phase I samples, higher viscosities were partly caused by the gums present in the formulations, which have a thickening effect (Lal et al., 2006). As discussed earlier, increases in apparent viscosity were enhanced by SHMP and potassium citrate by dissociating casein micelles into serum phase.

The increase in apparent viscosity was more prominent in the control than in MPC-20 as SHMP increased from 0 to $0.25 \%$. As explained for phase I, this is the result of varying calcium concentrations, which could change the extent of casein micelle dissociation and formation of calcium-casein phosphate complexes with addition of SHMP, as illustrated in Figure 1. As in phase I, apparent viscosity of control, MPC-20, and
MPC-30 in the absence of SHMP in phase II did not differ.

Heated Formulations. Heated formulations in phase II had much higher apparent viscosities than the corresponding heated solutions of phase I. On heating, components of the formulation such as gums tend to react with $\kappa$-caseins and form a network. This network binds to water molecules, increasing apparent viscosity and hydrating and stabilizing the proteins (Lal et al., 2006). Increased total solids and the presence of carbohydrates also increased the protein hydrodynamic volume after heat treatment and consequently the viscosities of the formulations (Gao et al., 2010; Chen and O'Mahony, 2016).

Control formulations exhibited a significant $(P<$ $0.05)$ increase in apparent viscosity from $124.66 \mathrm{cP}$ at $0 \%$ SHMP to $235.61 \mathrm{cP}$ at $0.15 \%$ SHMP, but 0.15 and $0.25 \%$ SHMP control formulations did not differ from each other. In MPC-20, the lowest apparent viscosities of 97.88 and $100.78 \mathrm{cP}$ were observed at 0 and $0.15 \%$ SHMP, respectively, and a significant $(P<0.05)$ increase in apparent viscosity to $237.75 \mathrm{cP}$ was observed with $0.25 \%$ SHMP. This viscosity increase with added SHMP in phase II was due to the exposure of phosphoserine residues, leading to increased electrostatic repulsions as calcium was chelated. These repulsions caused dissociation of caseins from casein micelles, increasing the apparent viscosity. In contrast, MPC-30 showed 
no significant difference at any level of SHMP and observed viscosities were in the range of 168 to $186 \mathrm{cP}$. These relatively higher viscosities and different trend in MPC-30 compared with unheated MPC-30 was due to the aggregation of casein submicelles. Dissociated casein submicelles form aggregates on heating and are reported to continue growing in number and size until they form a gel, resulting in increases in apparent viscosity (Panouillé et al., 2004).

\section{Phase II: Particle Size}

Unheated Formulations. Particle size of phase II unheated formulations is given in Table 4, and the same trend was observed as in phase I. Particle size in control decreased significantly $(P<0.05)$ from 236 to $176 \mathrm{~nm}$, with an increase in SHMP concentration from 0 to $0.15 \%$, and decreased to $123 \mathrm{~nm}$ with addition of $0.25 \%$ SHMP. A similar observation was made in MPC20, where particle size decreased from 163 to $148 \mathrm{~nm}$ with $0.15 \%$ SHMP and to $126 \mathrm{~nm}$ with $0.25 \%$ SHMP. In MPC-30, particle size decreased from $135 \mathrm{~nm}$ at $0 \%$ to $112 \mathrm{~nm}$ at $0.15 \%$ SHMP, with no further change at the highest SHMP concentration. As described for apparent viscosity, dissociation of casein micelles was caused by both SHMP and potassium citrate in phase II. Particle size was significantly $(P<0.05)$ higher in the unheated control, followed by MPC-20 and MPC-30 in the absence of SHMP. Similar to phase I solutions, casein micelle dissociation did not influence the apparent viscosity of the formulations in this case.

Heated Formulations. In the heated formulations, a significant $(P<0.05)$ decrease in particle size from 263 to $246 \mathrm{~nm}$ was observed as SHMP increased from 0 to $0.25 \%$ in the control. Similarly, particle size decreased significantly $(P<0.05)$ from 252 to $214 \mathrm{~nm}$ in MPC-20 as SHMP increased from 0 to $0.25 \%$. This decrease was due to casein micelle dissociation by SHMP and potassium citrate in the formulation. However, in MPC-30, particle size increased from 315 to $331 \mathrm{~nm}$ as SHMP increased from 0 to $0.15 \%$ and decreased to $303 \mathrm{~nm}$ on further increase to $0.25 \%$ SHMP. These observations correlated well with phase II apparent viscosity data. The particle size increase in MPC-30 (in the absence of SHMP) was attributed to the interaction between dispersed casein aggregates and denatured whey proteins. The addition of $0.15 \%$ SHMP also increased mean particle size due to reaggregation of proteins, and further addition of SHMP caused casein micelle dissociation. In the absence of SHMP, particle size was not significantly different between control and MPC-20, but particle size did increase in MPC-30 because of casein micelle aggregation.

\section{Phase II: Color}

Unheated Formulations. Lightness did not differ in control formulations at any level of SHMP studied and ranged from 69 to 75 . In MPC-20, L* decreased significantly $(P<0.05)$ to 62 with $0.25 \%$ SHMP and did not change for 0 and $0.15 \%$ SHMP. The decrease with $0.25 \%$ SHMP was due to casein micelle dissociation, which reduced opacity in the formulations. In MPC-30, $\mathrm{L}^{*}$ did not change significantly at any level of SHMP studied and ranged from 62 to 67 . In the absence of SHMP, there was no significant difference between $\mathrm{L}^{*}$ values of control, MPC-20, and MPC-30.

Heated Formulations. We detected no significant interaction effect between calcium concentration of MPC and SHMP concentration main effects in $a^{*}, b^{*}$, or $\mathrm{L}^{*}$ of heated formulations. There were no significant differences in the main effects either, implying that color was not influenced by SHMP concentration or MPC calcium content. Upon heating, formation of brown pigments from the Maillard reaction was similar in all formulations studied (data not shown).

\section{Phase II: Heat Stability}

Heat coagulation times of phase II enteral formulations are shown in Figure 3; HCT values were generally lower than those of the corresponding phase I MPC solutions. Although phase I and II formulations contained the same amount of protein, the presence of other ingredients influenced the heat stability of phase II formulations. The presence of carbohydrates such as maltodextrin and sucrose is reported to negatively influence the heat stability of dairy beverage formulations and explain overall reduction in $\mathrm{HCT}$ observations in phase II of the current study (Chen and O'Mahony, 2016). Gao et al. (2010) also found that calcium ion activity increased in skim milk after addition of $10 \%$ sucrose, because of the combination of protein hydration and volume exclusion. These changes in calcium ion activity due to the composition of the formulation resulted in lower HCT in phase II than in phase I.

The HCT of control decreased significantly $(P<$ $0.05)$ as SHMP concentration increased from 0 (7.1 $\min )$ to $0.25 \%$ (3.8 min). In addition to SHMP, potassium citrate in the formulation could have contributed to the reduction in the HCT because it also acts as a chelator (Le Ray et al., 1998; Mizuno and Lucey, 2005; Kaliappan and Lucey, 2011). When calcium is chelated beyond its threshold limit, it destabilizes the casein micelles, inducing dissociation, causing aggregation, and decreasing heat stability (de Kort et al., 2012).

In MPC-20, HCT decreased significantly $(P<0.05)$ with 0.15 and $0.25 \%$ SHMP. The highest HCT was re- 


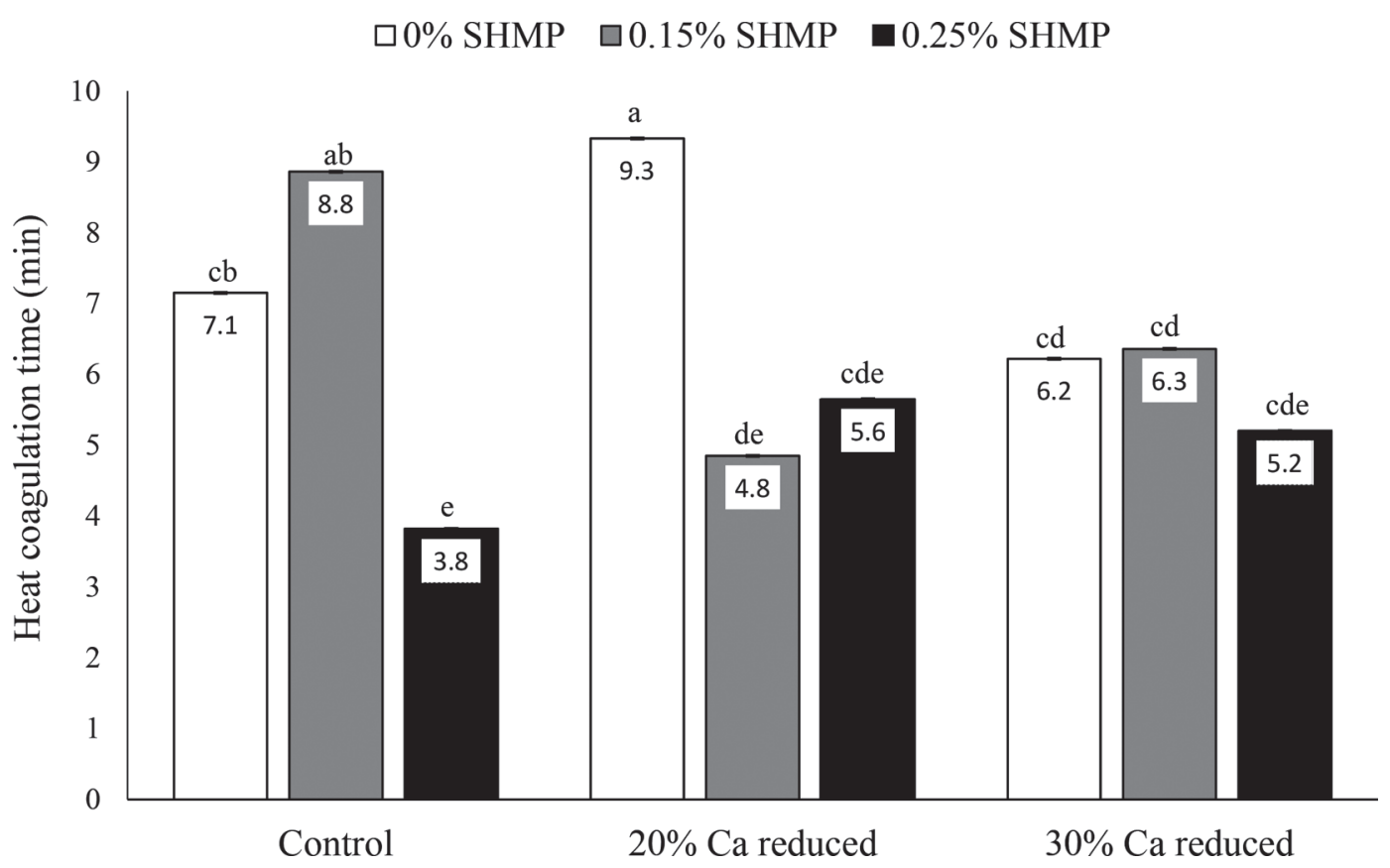

Figure 3. Heat coagulation time (HCT; min) of enteral dairy beverage formulations prepared using control, $20 \%$ calcium-reduced milk protein concentrate (MPC-20), and 30\% calcium-reduced MPC (MPC-30) in phase II with sodium hexametaphosphate (SHMP) at different levels. Values with the same letters (a-e) are not significantly different across all treatments $(P>0.05)$. Error bars indicate SD $(\mathrm{n}=2)$.

ported in MPC-20 with 0\% SHMP (9.3 min), whereas it ranged from 4 to 6 min in 0.15 and $0.25 \%$ SHMP. In MPC-30, HCT did not differ significantly $(P<0.05)$ at 0 and $0.15 \%$ SHMP and decreased significantly to 5.2 min with $0.25 \%$ SHMP.

In the absence of SHMP, the HCT of MPC-20 was $\sim 2$ min longer than that of control and MPC-30. This longer HCT was because of calcium chelation that could have occurred within the threshold limit (the amount of calcium to be chelated to keep the casein micelles stable, where chelation beyond this limit would destabilize casein micelles), keeping casein micelles stabilized. With addition of $0.15 \%$ SHMP, HCT of control was significantly higher $(P<0.05)$ than that of MPC-20 and MPC-30. The addition of $0.15 \%$ SHMP chelated calcium beyond a threshold, which destabilized the casein micelles. These results illustrate the importance of the amount of calcium and the amount to be chelated to attain optimum heat stability in dairy beverage formulations. Our study also opens an opportunity to use calcium-reduced MPC to improve heat stability without addition of SHMP as an ingredient in dairy beverage formulations.

\section{CONCLUSIONS}

In phase I MPC solutions, HCT increased as calcium was chelated by SHMP in the control; no change in
HCT was observed in MPC-20 and MPC-30 solutions. In phase II, a different trend was observed because of the presence of other ingredients. In phase II, MPC-20 with no SHMP had the highest heat stability; however, the addition of SHMP negatively affected HCT of MPC20 and MPC-30. In phases I and II, apparent viscosity increased with addition of SHMP, which was attributed to casein micelle dissociation because of calcium chelation. Particle size data supported the observations regarding casein micelle dissociation with SHMP addition. Dissociation of casein micelles, even in absence of SHMP, was observed in MPC-20 and MPC-30 because of the reduced calcium content, with the lowest apparent viscosity being observed in MPC-20. These results suggest that application of calcium-reduced MPC could improve heat stability, even in presence of other ingredients in the formulation. Enteral dairy beverages should be evaluated for storage stability when calciumreduced MPC are used as a primary ingredient. The use of calcium-reduced MPC in high-protein dairy beverages may allow elimination of chelating salts and thereby contribute to a consumer-friendly label.

\section{ACKNOWLEDGMENTS}

This project is Kansas State Research and Extension contribution number 18-270-J. The generous donation of MPC powders by Idaho Milk Products (Jerome, 
ID) is greatly appreciated. Use of names and names of ingredients is only for scientific clarity and does not constitute any endorsement of product by the authors or Kansas State University.

\section{REFERENCES}

Anema, S. G., D. N. Pinder, R. J. Hunter, and Y. Hemar. 2006. Effects of storage temperature on the solubility of milk protein concentrate (MPC85). Food Hydrocoll. 20:386-393.

Augustin, M. A. 2000. Mineral salts and their effect on milk functionality. Aust. J. Dairy Technol. 55:61-64.

Augustin, M.-A., and P. T. Clarke. 1990. Effects of added salts on the heat stability of recombined concentrated milk. J. Dairy Res. $57: 213-226$.

Chandrapala, J. J. S. 2009. Effect of concentration, pH and added chelating agents on the colloidal properties of heated reconstituted skim milk. PhD Thesis. Monash Univ., Australia.

Chen, B., and J. A. O'Mahony. 2016. Impact of glucose polymer chain length on heat and physical stability of milk protein-carbohydrate nutritional beverages. Food Chem. 211:474-482.

Crowley, S. V., M. Megemont, I. Gazi, A. L. Kelly, T. Huppertz, and J. A. O'Mahony. 2014. Heat stability of reconstituted milk protein concentrate powders. Int. Dairy J. 37:104-110.

Crudden, A., D. Afoufa-Bastien, P. F. Fox, G. Brisson, and A. L. Kelly. 2005. Effect of hydrolysis of casein by plasmin on the heat stability of milk. Int. Dairy J. 15:1017-1025.

de Kort, E., M. Minor, T. Snoeren, T. van Hooijdonk, and E. van der Linden. 2011. Effect of calcium chelators on physical changes in casein micelles in concentrated micellar casein solutions. Int. Dairy J. 21:907-913.

de Kort, E., M. Minor, T. Snoeren, T. van Hooijdonk, and E. van der Linden. 2012. Effect of calcium chelators on heat coagulation and heat-induced changes of concentrated micellar casein solutions: The role of calcium-ion activity and micellar integrity. Int. Dairy J. 26:112-119

Faka, M., M. J. Lewis, A. S. Grandison, and H. Deeth. 2009. The effect of free $\mathrm{Ca}^{2+}$ on the heat stability and other characteristics of low-heat skim milk powder. Int. Dairy J. 19:386-392.

Fang, Y., S. Rogers, C. Selomulya, and X. D. Chen. 2012. Functionality of milk protein concentrate: Effect of spray drying temperature. Biochem. Eng. J. 62:101-105.

Gao, R., H. P. van Leeuwen, E. J. Temminghoff, H. J. van Valenberg, M. D. Eisner, and M. A. van Boekel. 2010. Effect of disaccharides on ion properties in milk-based systems. J. Agric. Food Chem. 58:6449-6457.
Griffin, M. C. A., R. L. J. Lyster, and J. C. Price. 1988. The disaggregation of calcium-depleted casein micelles. Eur. J. Biochem. 174:339-343.

Kaliappan, S., and J. A. Lucey. 2011. Influence of mixtures of calcium-chelating salts on the physicochemical properties of casein micelles. J. Dairy Sci. 94:4255-4263.

Lagrange, V., D. Whitsett, and C. Burris. 2015. Global market for dairy proteins. J. Food Sci. 80:A16-A22.

Lal, S. N. D., C. J. O'Connor, and L. Eyres. 2006. Application of emulsifiers/stabilizers in dairy products of high rheology. Adv. Colloid Interface Sci. 123-126:433-437.

Le Ray, C., J.-L. Maubois, F. Gaucheron, G. Brulé, P. Pronnier, and F. Garnier. 1998. Heat stability of reconstituted casein micelle dispersions: changes induced by salt addition. Lait 78:375-390.

Marella, C., P. Salunke, A. C. Biswas, A. Kommineni, and L. E. Metzger. 2015. Manufacture of modified milk protein concentrate utilizing injection of carbon dioxide. J. Dairy Sci. 98:3577-3589.

McCarthy, N. A., O. Power, H. B. Wijayanti, P. M. Kelly, L. Mao, and M. A. Fenelon. 2017. Effects of calcium chelating agents on the solubility of milk protein concentrate. Int. J. Dairy Technol. $70: 415-423$.

Mizuno, R., and J. A. Lucey. 2005. Effects of emulsifying salts on the turbidity and calcium-phosphate-protein interactions in casein micelles. J. Dairy Sci. 88:3070-3078.

Nasirpour, A., J. Scher, M. Linder, and S. Desobry. 2006. Modeling of lactose crystallization and color changes in model infant foods. J. Dairy Sci. 89:2365-2373.

Panouillé, M., T. Nicolai, and D. Durand. 2004. Heat induced aggregation and gelation of casein submicelles. Int. Dairy J. 14:297-303.

Pitkowski, A., T. Nicolai, and D. Durand. 2008. Scattering and turbidity study of the dissociation of casein by calcium chelation. Biomacromolecules 9:369-375.

Ramchandran, L., X. Luo, and T. Vasiljevic. 2017. Effect of chelators on functionality of milk protein concentrates obtained by ultrafiltration at a constant $\mathrm{pH}$ and temperature. J. Dairy Res. $84: 471-478$

Silva, F. V., G. S. Lopes, J. A. Nóbrega, G. B. Souza, and A. R. A. Nogueira. 2001. Study of the protein-bound fraction of calcium, iron, magnesium and zinc in bovine milk. Spectrochim. Acta B Atomic Spectrosc. 56:1909-1916.

Singh, H. 2004. Heat stability of milk. Int. J. Dairy Technol. 57:111119.

Singh, H., and P. F. Fox. 1987. Heat stability of milk: Role of $\beta$-lactoglobulin in the $\mathrm{pH}$-dependent dissociation of micellar к-casein. J. Dairy Res. 54:509-521.

Xu, Y., D. Liu, H. Yang, J. Zhang, X. Liu, J. M. Regenstein, Y. Hemar, and P. Zhou. 2016. Effect of calcium sequestration by ionexchange treatment on the dissociation of casein micelles in model milk protein concentrates. Food Hydrocoll. 60:59-66. 